\title{
Um estudo sobre a autocompaixão e a satisfação da vida em idosos
}

\section{A study of self-compassion and life satisfaction in the elderly}

\author{
Jéssica Kalckmann Gilgen ${ }^{1}$
}

Maikon de Sousa Michels ${ }^{2}$

Resumo: O presente artigo teve como objetivo avaliar o nível de autocompaixão e satisfação da vida em idosos. Para a realização do trabalho, foram aplicadas as escalas de autocompaixão e de satisfação da vida, assim como um questionário sociodemográfico em 25 idosos da região de Joinville, Santa Catarina. Entre eles, havia participantes residentes em lares para idosos e participantes que residiam com familiares ou sozinhos, sendo que todos apresentavam idade entre 69 e 90 anos. Para a análise de dados foi utilizado o programa IBM-SPSS que gerou um Coeficiente de Pearson, visando realizar a correlação entre a autocompaixão e a satisfação de vida, assim como da autocompaixão/satisfação de vida em relação à idade, estado civil, percepção de saúde, local de residência e situação financeira. Como resultado foi possível analisar que mais de $70 \%$ dos participantes apresentam percentis acima de 50, que significam níveis médios e altos, tanto para a autocompaixão como para a satisfação da vida. Além disso, a autocompaixão e a satisfação de vida em idosos possuem uma correlação significativa, assim como a autocompaixão com o estado civil do participante e com a idade do mesmo. A satisfação da vida teve correlação significante com percepção de saúde do indivíduo. As outras variáveis analisadas não apresentaram correlação com a autocompaixão ou com a satisfação da vida.

Palavras-chave: Velhice, autocompaixão, satisfação de vida, Terapia focada na compaixão.

\begin{abstract}
The present article aimed to evaluate the level of self-compassion and life satisfaction in the elderly. For the accomplishment of the work, self-compassion and life satisfaction scales were applied, as well as a sociodemographic questionnaire in 25 elderly people from Joinville, Santa Catarina. Among them were participants residents of nursing homes and participants residing with relatives or alone, all of whom were between 69 and 90 years old. For data analysis, the IBM-SPSS program was used, which generated a Pearson Coefficient, aiming to correlate self-compassion and life satisfaction, as well as selfcompassion / life satisfaction in relation to age, marital status, perception of health, place of residence and financial situation. As a result it was possible to analyze that more than $70 \%$ of the participants present percentiles above 50, both for self-compassion and life satisfaction. Besides that, self-compassion and life satisfaction in the elderly have a significant correlation, as does self-compassion with the participant's marital status and age. Life satisfaction was

${ }^{1}$ Psicóloga formada pelo curso de Psicologia da Universidade da região de Joinville (UNIVILLE)

2 Professor orientador do curso de Psicologia da Universidade da região de Joinville (UNIVILLE)
\end{abstract}


correlated with the individual's health perception. The other variables analyzed were not correlated with self-compassion or life satisfaction.

Key-words: Age, self-compassion, life satisfaction, Compassion-focused therapy.

\section{Introdução}

A Organização Mundial de Saúde - OMS (2015), em seu relatório sobre o envelhecimento e saúde, traz que na atualidade, é algo natural viver mais que 60 anos. Além disso, a taxa de pessoas entrando na idade da velhice é cada vez maior (OMS, 2015,web): "Em apenas 35 anos, essa taxa terá aumentado em torno de 1 a cada 3 . E o ritmo de envelhecimento da população é muito mais rápido que no passado".

De 1950 até 2020, a projeção de aumento da taxa de pessoas acima de 60 anos no Brasil terá um crescimento de 16 vezes, enquanto as outras faixas etárias da população crescerão apenas 5 vezes (VERAS et. al. 2001). Quando comparado com o valor de outros locais, países como Estados Unidos, China e Japão terão crescimentos entre 3 e 6,5 da população idosa, tendo uma diferença assim de mais de 10 vezes se comparado com o crescimento atual no Brasil, o que demonstra que o crescimento da população idosa brasileira ocorre de forma muito mais rápida no território nacional do que em outras regiões internacionais (VERAS et. al. 2001).

Com a chegada da velhice, de acordo com a OMS (2015), percebe-se a oportunidade de pensar e repensar no que a vida pode se desdobrar. Dessa forma, surge a questão de como o indivíduo que está entrando nesse período da vida pode refletir sobre si e sobre o que já viveu. A autocompaixão, diferentemente da autopiedade (que é a pena de si mesmo), trata a questão de como as pessoas lidam consigo mesmas quando erram, fracassam, quando sofrem, ou seja, como lidam com os momentos difíceis que passam ao longo da vida (NEFF, 2003a apud HUTZ, 2014). Uma pessoa autocompassiva não evita acontecimentos/sentimentos, sejam eles bons ou ruins, mas tem o desejo de cuidar de si e do próximo com compreensão e tolerância (PARENTE et. al. 2018).

Ao analisar o que o indivíduo viveu ao longo da vida, outro fator a ser estudado é a satisfação da vida, que "pode ser entendida como o nível de entusiasmo e prazer ou descontentamento e sofrimento presente na vida de uma pessoa de acordo com a sua percepção do que é satisfatório e/ou desprazeroso" (DIENER, LUCAS e OISHI, 2005 apud HUTZ 2014, p.43). Dessa forma, o presente artigo teve como objetivo principal avaliar o nível de 
autocompaixão e de satisfação da vida em idosos, e como objetivos secundários comparar o nível de autocompaixão e de satisfação da vida analisando se existe correlação entre estes dois fatores, e avaliar se os dados do questionário sociodemográfico como local de residência, condição de saúde, idade, condição financeira e estado civil possuem correlação com a satisfação da vida e com a autocompaixão em idosos.

Logo, o estudo com idosos torna-se importante diante do rápido aumento da população que está entrando nessa etapa da vida. Avaliar a autocompaixão e a satisfação da vida em idosos traz os benefícios de se ter um maior entendimento sobre a questão da velhice na sociedade. Além disso, pode apresentar um maior entendimento sobre como a autocompaixão pode influenciar numa velhice saudável (com relação ao autocuidado, com o cuidado ao próximo, com as relações que mantém), e como a satisfação com a vida pode ser um fator de influência no processo de envelhecimento e na saúde mental (nas cognições, nas emoções e nos relacionamentos). Com esse trabalho, tem-se a possibilidade de entender como esses dois fatores podem influenciar no desenvolvimento dessa última etapa da vida, e assim, como podem ser tratados para que o envelhecimento se torne saudável e gere um maior bem-estar para o indivíduo.

Esse manuscrito está organizado da seguinte forma: a seguir, será descrita a fundamentação teórica utilizada para embasar esse estudo. Após a descrição da parte teórica, a metodologia utilizada será explicada. Em sequência, os resultados serão apresentados e discutidos e por fim, as considerações finais.

\section{Fundamentação teórica}

O aumento da população com idade acima de 60 anos fez com que a elevada taxa de pessoas na velhice passasse a ser um fenômeno mundial que ocorre no Brasil de forma acelerada (VERAS, 2009). Desta forma, pode-se prever que em 2020 o Brasil será o sexto país com a maior população de idosos (acima de 30 milhões de indivíduos). Como afirma Carvalho, (2003 apud VERAS 2009, p.549):

O Brasil hoje é um “jovem país de cabelos brancos”. A cada ano, 650 mil novos idosos são incorporados à população brasileira, a maior parte com doenças crônicas e alguns com limitações funcionais. Em menos de 40 anos, o Brasil passou de um cenário de mortalidade próprio de uma população jovem para um quadro de enfermidades complexas e onerosas, típica dos países longevos, caracterizado por doenças crônicas e múltiplas que perduram por anos, com exigência de cuidados constantes, medicação contínua e exames periódicos. 
A velhice é a última fase do ciclo vital, sendo um processo gradual de declínio, seja da estrutura, da função, ou da organização do organismo do indivíduo, em que a etapa final é a morte. O processo da velhice em humanos pode depender do desenvolvimento fisiológico e psicológico que o indivíduo atingiu em sua vida, além de questões genéticas, de recursos sociais (como medicamentos, recursos econômicos), e tecnológicos (NERI, 2013). Atualmente, com a velhice pode-se ver também um aumento da expectativa de vida, assim como, uma diminuição do grau de deficiências (tanto mental como física) juntamente a uma redução da pobreza/indigência (CARAMANO, 2002).

O processo de envelhecimento, além de ser um fenômeno biológico, é também uma questão cultural, pois em algumas sociedades o ato de envelhecer é visto como algo negativo, indesejável e possível de gerar sofrimento no indivíduo, contrapondo com a juventude, que é vista como algo desejável e bonito (MOREIRA e NOGUEIRA, 2008). Essa comparação pode ser vista também em relação ao trabalho, pois o envelhecimento se encontra fora da sociedade que está focada na produção e no rendimento, podendo gerar uma exclusão dessa parte da população do sistema político e econômico, gerando assim a possibilidade de perder seu emprego para outro indivíduo mais jovem (MOREIRA e NOGUEIRA, 2008).

O envelhecimento traz diversas modificações para o organismo humano, como alterações na audição, visão, sistema imunológico, sistema endócrino e metabólico, sistema hormonal, sistema cardiovascular, respiratório, geniturinário, gastrointestinal e hepático (MALLOY-DINIZ, FUENTES e CONSENZA, 2013). Juntamente a estes, aparecem problemas relacionados à diminuição da densidade óssea e das células articulares do corpo, como as cartilagens, assim como, ocorre uma degeneração progressiva na pele (que se torna mais seca, enrugada, fina e descamativa) (BICALHO e CINTRA, 2013). Ainda para os autores, na velhice podem surgir problemas como o aumento da porcentagem de gordura e diminuição da massa magra/densidade óssea, que podem gerar um aumento de doenças cardiovasculares e diabetes, assim como disfunção muscular que aparece nessa etapa da vida e pode acarretar em fraqueza física, lentidão nos movimentos ou em perda da mobilidade (BICALHO e CINTRA, 2013).

Além de mudanças físicas, podem aparecer modificações neurológicas e psicológicas, sendo elas, perdas sensoriais e psicomotoras, como a atenção, concentração e o controle motor, assim como perdas de memória, de funções cognitivas e da capacidade funcional do idoso (FREITAS, BARBOSA e NEUFELD, 2015). Para as autoras, a capacidade funcional é fundamental para a autonomia do indivíduo, pois envolve a realização de atividades diárias como autocuidado, alimentar-se, continência urinária, higienização, locomoção e atividades diárias mais complexas, como fazer compras, usar meios tecnológicos, trabalhar, viajar e 
manter contatos sociais.

Com o decorrer das mudanças físicas e psicológicas, e o avançar da idade, muitas pessoas quando chegam na velhice se mantêm vivendo sozinhos em suas residências, ou passam a residir com familiares e/ou com cuidadores. Desta forma, a família desse idoso possui um papel fundamental para uma velhice bem-sucedida, pois acaba assumindo papel de responsável pelo atendimento das necessidades apresentadas pelo mesmo (PAIVA et. al. 2011). Muitos idosos que contam com uma boa rede de apoio familiar, acabam tornando o processo da velhice muito mais tranquilo e satisfatório (MJ et. al. 2004, apud PAIVA et. al. 2011).

Além disso, muitos indivíduos passam a residir em instituições de apoio ao idoso, que também ajudam como promovedoras de elos para os que estão ali residentes. Como Junior e Tavares (2004, p.153) apresentam, "sabemos que a rede social pessoal apresenta uma tendência a diminuir à medida em que se envelhece, necessidade que pode se tornar mais intensa quando tratamos do idoso institucionalizado". Logo, com a diminuição do contato com parentes, familiares e amigos, a instituição na qual o idoso reside passa a ser uma forma de "elo" entre o idoso e suas redes de contatos.

Neste contexto em que o idoso pode estar entre sua rede de contatos familiares, ou em uma rede social formada pela instituição na qual está inserido, torna-se relevante estudar como este idoso se percebe e como ele percebe a vida na qual está vivendo. Desse modo, a forma como a autocompaixão se apresenta nestes indivíduos pode influenciar na percepção e na vivência da vida, pois, a autocompaixão está associada a forma como o ser humano lida com as situações cotidianas, assim como, com a maneira como lida consigo mesmo, ou seja, se autocriticando, ou tendo compaixão por si e aceitando seus erros e suas falhas, sem se julgar ou se punir (PARENTE et. al. 2018). Logo, a autocompaixão quando voltada à velhice torna-se importante, pois, avaliar o nível de autocompaixão em idosos possibilita um maior entendimento sobre as percepções de que os mesmos têm sobre essa etapa do ciclo da vida.

A compaixão é uma mentalidade do ser humano capaz de se dividir e se dirigir por três direções diferentes dentro do mesmo campo. Dentre essas formas, existe a compaixão que o homem é capaz de sentir pelo próximo; a compaixão que o outro é capaz de sentir pelo homem e que este é capaz de senti-la e percebê-la e por fim, uma terceira direção que é a compaixão que pode sentir por si mesmo, denominada dessa forma como autocompaixão (GILBERT, 2014).

Além disso, a autocompaixão é o fator que permite que o indivíduo tenha sentimentos de perceber-se conectado com os outros, além de ser responsável por diminuir os sentimentos e sensações geradas pela separação/afastamento ou pela ideia de sentir-se abandonado/sozinho 
(NEFF 2003a, 2003b apud PARENTE, 2016).

A autocompaixão pode ser definida segundo três componentes básicos: Capacidade
para ser compreensível e amável para consigo próprio, em vez de ser punitivo e crítico
(Calor/ Compreensão vs. Autocriticismo); entender as suas experiências como parte
de uma experiência humana maior (Condição humana vs. Isolamento) e consciência
equilibrada dos próprios pensamentos e sentimentos dolorosos, sem uma excessiva
sobreidentificação (Mindfulness vs. Sobre-identificação) (NEFF, 2003 apud
PARENTE, 2016, p.4).

Para a Terapia Focada na Compaixão (TFC), a compaixão surge nos comportamentos do indivíduo, que podem ser eles comportamentos altruístas e comportamentos de cuidado. O comportamento altruísta faz com que o indivíduo busque suas metas, seja para o alívio de seu sofrimento, ou para o alívio do sofrimento dos outros ao seu redor, enquanto que o comportamento do cuidado, pode ser tanto o de cuidar dos outros, como o de ser cuidado por outros (GILBERT 1989, 2005, apud GILBERT, 2010). Dessa forma, torna-se possível perceber que os comportamentos de cuidados na fase da velhice passam a ser primordiais para o bemestar do idoso, seja esse cuidado, gerado pelo próprio indivíduo (autocuidado) ou por seus responsáveis (familiares/cuidadores), assim como pelo cuidado que pode ter para com o próximo (GILBERT 1989, 2005, apud GILBERT, 2010).

Outro ponto de ser analisado na velhice é a satisfação da vida, pois analisar esse fator permite gerar uma compreensão geral da vida do indivíduo, sendo que essa compreensão é algo subjetivo daquele que à vivenciou. Cada indivíduo interpreta os acontecimentos da sua vida de forma diferente, e por este motivo, entender e analisar os níveis de satisfação da vida torna-se importante para entender como o indivíduo enfrentou os acontecimentos ao longo da vida até chegar na velhice.

A satisfação da vida trata-se de um fenômeno de difícil mensuração, pois a satisfação em relação à vida é algo subjetivo de cada indivíduo, e dessa forma, para defini-la, é possível apenas por meio de um julgamento cognitivo de áreas da vida, como o trabalho do indivíduo, a saúde, suas relações sociais ao longo da vida, a autonomia ou independência que possui, suas condições de moradia, e outros pontos relacionados com a sua vida até determinado momento (JOIA et. al. 2006).

A satisfação da vida não é algo estático, ou seja, não é algo que se define e que ocorre em apenas uma etapa/momento da vida, mas sim, são diversos momentos e situações ao longo dos anos de forma contínua e que depende de inúmeros fatores, sendo que esses acontecimentos podem aumentar ou diminuir a satisfação com a vida durante aquele período vivido (JOIA e RUIZ, 2013). Logo, as experiências vivenciadas ao longo da vida, seja no passado, no presente, 
ou incluso desejos sobre as experiências futuras fazem com que a satisfação da vida esteja vinculada à história pessoal do indivíduo, ajudando assim, na compreensão de si próprio e da satisfação que sente (JOIA e RUIZ, 2013).

Portanto, a satisfação da vida em idosos junto à autocompaixão pode melhorar a qualidade de vida, assim como, gerar melhores sentimentos e emoções. Além disso, estudar esses dois constructos é estudar a saúde mental dos idosos, não apenas estudando e avaliando transtornos físicos ou mentais, mas, estados mentais saudáveis e formas de enfrentamento diante as adversidades do dia a dia. O conceito de saúde não é apenas a falta de doenças, pois a saúde depende também do bem-estar físico, social e mental dos indivíduos (OMS, 1946 apud ONUBR, 2016). Dessa forma, para entender a saúde do idoso, é necessário entender como o mesmo viveu, e como percebe a sua vida. Além disso, baixos níveis de autocompaixão podem estar relacionados à vergonha, autocrítica, e psicopatologias, que são fatores que podem influenciar no desenvolvimento do indivíduo, assim como na satisfação que o mesmo sente em relação à sua vida e ao seu bem-estar. Logo, tanto a satisfação da vida como a autocompaixão buscam trabalhar com as formas de enfrentamento, com as formas de interpretação daquilo que acontece com os indivíduos no dia a dia, assim como com as formas de ver a si mesmo e a sua vida, tornando-se assim, fatores importantes de serem discutidos e analisados.

\section{Procedimentos metodológicos}

A realização da pesquisa ocorreu por meio da avaliação das respostas de 25 idosos com idade entre 69 e 90 anos, em que, 3 desses idosos são do sexo masculino e 23 do sexo feminino, todos residentes em Joinville, sendo 8 participantes que residem em casas/lares para idosos, e 17 que residem sozinhos ou com seus familiares.

Para a coleta de dados, foram utilizadas duas escalas: Escala da autocompaixão - Como eu lido comigo em momentos difíceis (HUTZ, 2016), que busca analisar o nível de autocompaixão do indivíduo por meio de 26 itens que representam a ideia de autocompaixão, englobando questões sobre mindfulness, sobre identificação, isolamento, bondade consigo, senso de humanidade e autocrítica. Para responder cada pergunta, o participante deve escolher um valor de 1 a 5, sendo 1 "quase nunca" e 5 "quase sempre". Para a interpretação dos dados, os valores são somados de acordo com as questões englobadas por cada um dos assuntos, gerando assim um escore bruto que, posteriormente, por meio de uma tabela, gera os percentis de cada participante. 
O outro instrumento, a Escala da satisfação de vida (HUTZ, 2014), visa identificar o nível de entusiasmo/prazer ou descontentamento/sofrimento na vida do indivíduo. Essa escala é composta por cinco itens de autorrelato, que devem ser preenchidos pela escala Likerd (participante deve preencher de 1 a 7 cada pergunta, em que 1 significa "discordo plenamente", e 7 "concordo plenamente", os valores intermediários significam que quanto mais próximo do 1, mais o participante discorda da afirmação, e que quanto mais próximo do 7, mais ele concorda). Após o preenchimento das 5 perguntas, o valor de cada resposta é somado, gerando assim um Escore bruto que posteriormente é transformado em percentil por meio da tabela de percentis.

Além das escalas, também foi utilizado um questionário sociodemográfico criado para identificar questões particulares, como escolaridade, trabalho, renda, saúde e outros. A coleta de dados foi aplicada em dois locais diferentes, sendo o primeiro deles um grupo de encontros de idosos, totalizando 19 participantes no grupo, e para os idosos residentes em lares, a aplicação ocorreu no local onde residem.

Para a análise de dados foi utilizado o programa IBM-SPSS Statistics para que assim os resultados pudessem ser comparados entre si usando o Coeficiente de Correlação de Pearson. Estes dados foram analisados em relação ao escore obtido de cada participante, além da comparação feita entre os dados obtidos das diferentes escalas/questionário. Desta forma, foram escolhidas as variáveis referentes à: Nível de autocompaixão, nível de satisfação com a vida, estado civil, idade dos participantes, local onde residem, condição de saúde e situação financeira para serem discutidos e analisados. Para a realização do estudo o projeto de pesquisa foi previamente aprovado pelo Comitê de Ética (CEP) com o número de Parecer 3.382.478.

\section{Análise e discussão dos resultados}

A partir da análise de dados foram criados tópicos relacionados à satisfação da vida e à autocompaixão, para que assim estes dados fossem correlacionados com os dados obtidos no questionário sociodemográfico, gerando então, uma comparação entre esses dois fatores juntamente à idade, estado civil, situação financeira, condição de saúde e local de residência.

\section{- Percentil de Autocompaixão e Satisfação da vida:}


Gráfico 1: Nível de autocompaixão e nível de Satisfação de vida em Percentil

Satisfação da vida $\square$ Autocompaixão

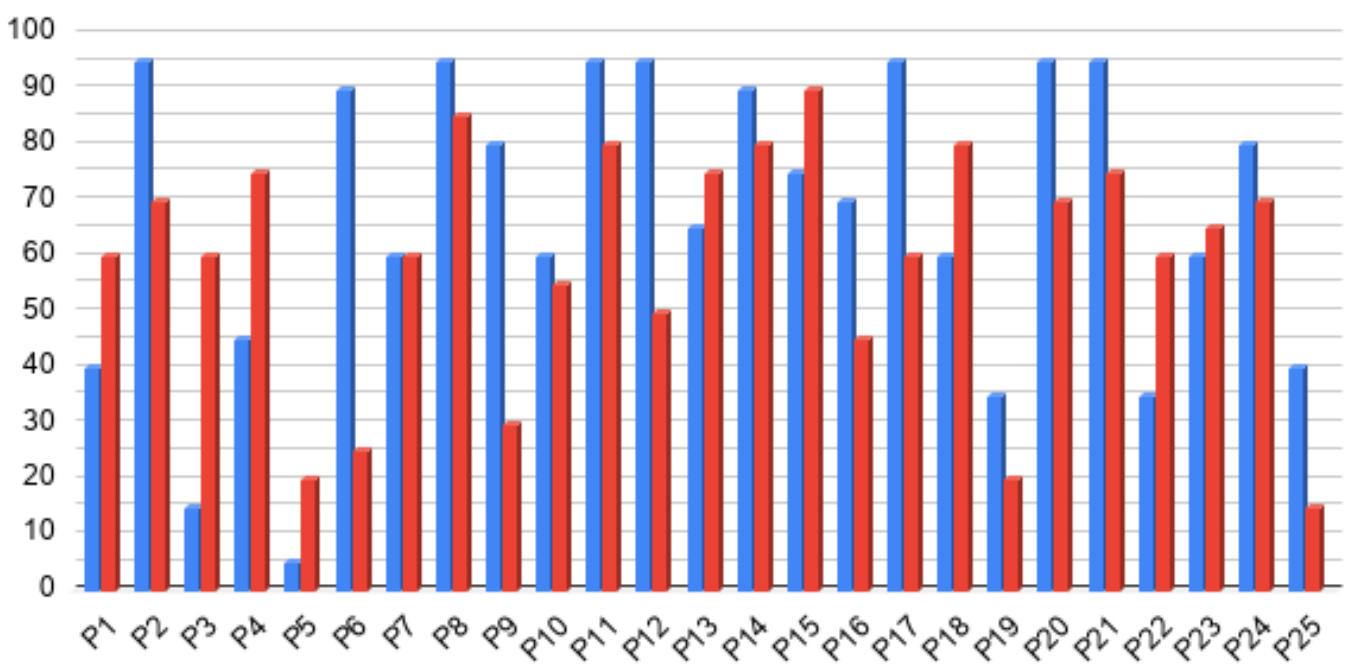

Fonte: Própria (2019).

Com a aplicação da escala de autocompaixão, pôde-se perceber que dos 25 participantes, os valores de autocompaixão variaram entre valores baixos (percentil entre 0 e 35), valores médios (entre 40 e 65) e valores altos de autocompaixão (entre 70 e 100). Dentre esses valores, $72 \%$ dos participantes apresentaram valores com percentil acima de 50, o que demonstra que mais da metade dos participantes estão com valores entre médio e alto de autocompaixão. Enquanto que apenas $28 \%$ dos participantes se encontram com percentis abaixo de 50 (Gráfico 1). Em relação aos valores de Satisfação da vida, $72 \%$ dos participantes apresentaram uma satisfação de vida com percentil acima de 50 e apenas $28 \%$ apresentaram uma satisfação da vida abaixo de 50, o que demonstra que mais da metade dos participantes se encontra com altos níveis de satisfação da vida (Gráfico 1).

A autocompaixão e a satisfação de vida em idosos tornam-se relevantes, pois uma maior autocompaixão pode gerar comportamentos que visam buscar alívio para o sofrimento do indivíduo, assim como comportamentos de autocuidado, sejam estes em relação à higiene, ao bem-estar, à forma como se percebem dentro da sociedade, dentre outros. Para os autores PintoGouveia, Duarte, Matos e Fráguas, (2013 apud PARENTE, 2016, p.3) “a autocompaixão, enquanto estratégia de regulação emocional, pode, na verdade, encorajar a aquisição destes comportamentos adaptativos, proporcionando uma mudança efetiva no incremento da saúde e do bem-estar". Logo, indivíduos com maior autocompaixão tendem a cuidar mais de si, aliviando problemas relacionados à velhice e melhorando a sua qualidade de vida. Além disso, idosos com maior autocompaixão conseguem cuidar melhor da sua saúde, com comportamentos 
menos autodestrutivos e com menos julgamentos sobre si mesmo.

Além disso, “[...] a autocompaixão implica o desenvolvimento de motivação genuína para o cuidado com o bem-estar pessoal, envolvendo ainda a compreensão empática através de uma atitude de não julgamento das experiências de vida" (GILBERT, 2005, apud PARENTE, 2016, p.4). Dessa forma, pessoas mais autocompassivas tendem a aceitar mais aquilo que acontece ao longo da vida, sendo essas situações ou emoções boas e ruins, ou seja, a autocompaixão fornece ferramentas para o indivíduo se entender e se aceitar melhor, para que assim aceite seus erros, seu sofrimento, e consiga então ter controle sobre si mesmo. Acreditamos, então, que indivíduos com maior autocompaixão conseguem passar por uma velhice mais proveitosa, pois ao conseguir se aceitar e aceitar aquilo que acontece consigo, passam a perceber os momentos e as mudanças de forma menos dolorosa.

Entrar em contato com a tristeza da realidade do sofrimento (por conta do que somos
- com vidas curtas, vulneráveis a doenças e com cérebros "complicados" - e nada
disso nós escolhemos ser) pode ser um estímulo para a compaixão e o desejo de
realizar mudanças e tomar o controle da própria vida. A compaixão nos faz querer
tomar a responsabilidade de mudar e fazer o que podemos para nos engajarmos e
ajudarmos com nosso sofrimento e o dos outros. (GILBERT, 2014 p.39)

Da mesma forma, a satisfação da vida relatada pelos participantes da pesquisa pode estar relacionada com diversos fatores, entre eles a saúde, os relacionamentos interpessoais, trabalho, moradia e outros. Além disso, a satisfação com a vida se torna importante nesta etapa da velhice, pois com todas as alterações fisiológicas e cognitivas que o indivíduo pode passar, a satisfação ainda depende de uma comparação entre o padrão que é pré-estabelecido pela sociedade (aquilo que é aceito, que é bom, que é desejável para a vida de todos) e aquilo que as circunstâncias da vida do indivíduo apresenta, fazendo com que a satisfação possa tornar-se uma comparação da própria vida com a dos outros (JOIA et.al. 2006). Ainda de acordo com a autora, a satisfação de vida muitas vezes pode ser vista associada a questões como autonomia e dependência, que surgem na velhice juntamente com as questões de saúde física/cognitiva, ou seja, uma maior satisfação da vida pode gerar maior independência por parte dos indivíduos, além de gerar sentimentos de bem-estar e assim conjuntamente com a autocompaixão, gerar uma velhice mais saudável e positiva para os indivíduos.

Logo, como mais da metade dos participantes apresentaram percentis acima de 50 tanto para satisfação da vida como para autocompaixão, cria-se a hipótese de que nessa etapa da vida, para o grupo que foi avaliado, a autocompaixão que foi consolidada ao longo dos anos tem um papel importante para o idoso, pois influencia no cuidado que este tem consigo mesmo, assim como na maneira como se vê e como interpreta a vida. Dessa forma, a autocompaixão para os 
idosos participantes, se torna fundamental, pois é através dela que o idoso pode se sentir cuidado e bem consigo. Além disso, a satisfação da vida por ser algo que foi construído de forma subjetiva por cada indivíduo, indica que os participantes tiveram boas vivências ao longo da vida, que podem estar conectadas com inúmeros fatores, entre eles, a autocompaixão.

\section{- Correlação entre Autocompaixão e Satisfação da vida:}

Quadro 1: correlação entre Autocompaixão e satisfação de vida

\begin{tabular}{|c|c|c|}
\hline & & $\begin{array}{l}\text { Nível de Autocompaixão do } \\
\text { participante }\end{array}$ \\
\hline $\begin{array}{l}\text { Nível de Satisfação da vida do } \\
\text { participante }\end{array}$ & $\begin{array}{l}\text { Correlação de Pearson } \\
\text { Significância (2-tailed) }\end{array}$ & $\begin{array}{r}0,424^{*} \\
0,035\end{array}$ \\
\hline
\end{tabular}

*Correlação é significante até o nível 0,05.

Fonte: Própria (2019)

A autocompaixão e satisfação de vida em idosos, de acordo com o Coeficiente de correlação de Pearson, possui um coeficiente de 0,424 (Quadro 1), demonstrando assim, existir uma correlação positiva significativa entre as duas variáveis. Essa correlação pode significar que a autocompaixão e a satisfação de vida estão correlacionadas com os momentos bons de cada pessoa, assim como com às formas de enfrentamento para diferentes situações, ou seja, níveis mais elevados de autocompaixão e de satisfação com a vida podem gerar enfrentamentos mais saudáveis e eficazes diante de situações boas ou ruins que podem aparecer na velhice, além disso, podem ajudar também a lidar com momentos difíceis de sofrimento e de angústia.

A satisfação da vida é a representação mental, ou seja, é a forma como o indivíduo interpreta e percebe a sua vida, em relação com o que pode estar dentro das suas expectativas, assim como com a situação na qual está passando, dessa forma, a satisfação está conectada com o modo como o indivíduo se percebe e percebe o seu entorno (PAVOT e DIENER, 1993 apud PARENTE et al. 2018). Pode-se então, perceber que a satisfação de vida está conectada com o bem-estar do indivíduo, pois uma maior satisfação de vida leva à uma melhor percepção de si mesmo e daquilo que ocorreu consigo.

Por outro lado, a autocompaixão pode ser associada de forma positiva à satisfação de vida, assim como com a felicidade, com a inteligência emocional, com otimismo e outras características sociais que podem gerar afetos positivos nos indivíduos de maneira geral, além disso, ainda possibilita que o indivíduo se mostre mais aberto e sensível às situações de fracasso, 
fazendo com que não fuja do sofrimento, mas enfrente a situação (NEFF, 2003b, 2004, 2008; NEFF, RUDE, et al., 2007 apud FONTINHA, 2009).

Logo, o fato de existir uma correlação positiva entre autocompaixão e satisfação de vida demonstra que ambos constructos estão conectados e podem desenvolver-se juntos ao longo da vida, ou seja, ao enfrentar situações difíceis e momentos de angústia ou tristeza, a forma de enfrentamento autocompassiva pode gerar um sentimento de satisfação, fazendo com que o indivíduo autocompassivo possua mais satisfação da vida. Além disso, ao passar por momentos de satisfação, o indivíduo pode também gerar sentimentos de compaixão/autocompaixão, fazendo com que o desenvolvimento de um desses fatores acarrete no desenvolvimento do outro, tornando assim uma correlação positiva, pois os dois se desenvolvem juntos e na mesma proporção ao longo da vida.

\section{- Correlação entre Autocompaixão/Satisfação da vida e estado civil do participante:}

Quadro 2: correlação entre Autocompaixão/Satisfação da vida e estado civil do participante

\begin{tabular}{|c|c|c|c|}
\hline & & $\begin{array}{l}\text { Nível de Satisfação da } \\
\text { vida do participante }\end{array}$ & $\begin{array}{c}\text { Nível de Autocompaixão } \\
\text { do participante }\end{array}$ \\
\hline & Correlação de Pearson & 0,348 & $0,535^{*}$ \\
\hline Estado civil do participante & Significância & 0,089 & 0,006 \\
\hline
\end{tabular}

*Correlação é significante até o nível 0,05

Fonte: Própria (2019)

Em relação à autocompaixão quando comparada aos estados civis dos participantes, o Coeficiente de Pearson resultante foi de 0,535 (Quadro 2), mostrando que essa variável se enquadra como uma correlação positiva significativa. Enquanto que, os estados civis quando comparados com a satisfação de vida apresentam o coeficiente de 0,348 (Quadro 2), demonstrando possuir uma fraca correlação entre as variáveis. Dentre os 25 participantes, 8 são separados, 12 são viúvos, 4 são casados e apenas 1 é solteiro. Dessa forma, a análise de correlação foi realizada sem especificar qual estado civil possui maior correlação, ou seja, a correlação se dá com os estados civis no geral, entretanto, a maior parte dos participantes não se encontra mais em um relacionamento conjugal, pois estão na categoria de "viúvos", fazendo com que essa relação entre autocompaixão e o estado civil seja um indicador de que as relações 
matrimoniais tiveram/tem uma influência sobre a forma como os participantes se percebem hoje.

Dessa forma, a autocompaixão quando comparada com o estado civil dos participantes pode mostrar não apenas uma correlação com o estado civil atual, mas de como essa relação conjugal afetou no desenvolvimento da autocompaixão do indivíduo. De acordo com Yarnell e Neff (2013 apud PEREIRA, 2016) pessoas com mais autocompaixão possuem uma alta probabilidade de se comprometer sem criar dependências em relacionamentos amorosos, assim como menores níveis de turbulência emocional e um melhor estado de bem-estar no relacionamento. Pessoas com um maior grau de autocompaixão conseguem estabelecer relações amorosas e sociais mais positivas do que indivíduos com menor autocompaixão (CANAVARRO, DIAS e LIMA, 2006 apud PEREIRA, 2016). Participantes com autocompaixão e com uma vinculação segura sentem mais confiança em outros indivíduos e dessa forma se sentem mais confortáveis com a relação e proximidade emocional com outras pessoas. Logo, é possível perceber que níveis mais elevados de autocompaixão podem influenciar nos relacionamentos afetivos que o indivíduo mantém ao longo da vida, podendo assim, afetar o estado civil do mesmo.

Por outro lado, os estados civis do participante quando relacionados com o nível de satisfação da vida apresentaram uma fraca correlação, o que pode significar que essas relações sociais que o indivíduo vive ao longo da vida não interferem de forma permanente na forma como o mesmo interpreta a sua satisfação. As relações afetivas e sociais são formas dinâmicas que podem variar de indivíduo para indivíduo, assim como, podem depender da situação em que o mesmo se encontra e do tipo de relacionamento no qual ele está, além de outras variáveis

Logo, o estado civil de cada indivíduo avaliado de forma isolada não se torna relevante para a satisfação da vida, pois essa variável pode ser interpretada de inúmeras maneiras para cada participante e para cada momento de sua vida. Entretanto, "relações sociais significativas permitem o desenvolvimento do self, dão sentido às experiências e podem oferecer apoio, importantes elementos no processo de adaptação, principalmente em momentos de transição da vida adulta" (NOGUEIRA, 2001 apud RESENDE et al. 2006 web), fazendo assim com que o relacionamento ou o estado civil seja importante para o indivíduo na fase da velhice, em que o mesmo se encontra em um momento de transição e de mudanças dentro do estilo de vida, como por exemplo com relação ao trabalho, saúde e moradia. Dessa forma, os relacionamentos/estado civil podem ajudar no processo de adaptação da velhice, porém, não são primordiais em relação à satisfação que o indivíduo sente em relação à sua vida, sendo relevante apenas na sua autocompaixão. 


\section{- Correlação entre Autocompaixão/Satisfação da vida e idade do participante:}

Quadro 3: Correlação entre autocompaixão/satisfação da vida e idade do participante.

\begin{tabular}{|c|c|c|c|}
\hline & & $\begin{array}{c}\text { Nível de Satisfação da } \\
\text { vida do participante }\end{array}$ & $\begin{array}{c}\text { Nível de } \\
\text { Autocompaixão do } \\
\text { participante }\end{array}$ \\
\hline & Correlação de Pearson & 0,347 & $0,431^{*}$ \\
\hline Idade do participante & Significância & 0,089 & 0,031 \\
\hline
\end{tabular}

*Correlação é significante até o nível 0,05

Fonte: Própria (2019)

A autocompaixão relacionada com a idade de cada participante, apresentou um coeficiente de 0,431 (Quadro 3), o que demonstra que a idade possui uma correlação positiva significativa com a autocompaixão. Por outro lado, a satisfação de vida apresentou uma correlação fraca, sendo assim considerada como insignificante, com um coeficiente de 0,347 (Quadro 3). O fato da idade estar correlacionada positivamente com apenas um dos fatores demonstra que a autocompaixão, por ser positivamente correlacionada, conforme a idade avança, faz com que uma pessoa se torne mais autocompassiva com o passar dos anos. Por outro lado, a satisfação da vida não depende de uma idade para ser consolidada no indivíduo, pois a cada etapa da vida essa satisfação pode ser interpretada diferentemente. Portanto, mesmo a autocompaixão estando positivamente correlacionada com a satisfação da vida, elas não dependem dos mesmos fatores para serem consolidadas no indivíduo.

A idade tem uma relação com a percepção que o indivíduo tem da sua saúde, além disso, o aumento da idade também está relacionado com as mudanças nos papéis sociais, como por exemplo em relação ao trabalho, ou com a sociedade no geral, assim como com mudanças físicas e cognitivas (PARENTE et al. 2018).

O avançar da idade traz consigo questões relacionadas ao emocional, e as redes afetivas/sociais que o ser humano possui (SERRÃO, 2018). Dessa forma, para a autora, pessoas idosas colocam o foco da sua atenção naquilo que está acontecendo no presente, naquilo que podem realizar, gerando um maior aproveitamento do tempo que ainda possuem na vida. Além disso, a idade se torna importante, pois é na velhice que os indivíduos passam a se perceber e perceber o que já aconteceu ao longo dos anos em sua vida, de forma a repensar o que já foi vivido e planejar aquilo que ainda pode acontecer. Diante dessa situação, olhar-se com autocompaixão e não de forma crítica se torna fundamental para aceitar-se e sentir-se bem 
consigo.

Logo, a forma como os idosos passam a se perceber com essa mudança da idade e a mudança de si ao longo dos anos, está associada à autocompaixão, podendo ser de forma positiva, ou seja, com um alto nível de autocompaixão, em que o indivíduo não tenta fugir das suas emoções, nem fugir de situações que causem essas emoções, mas sim tenta encará-las para então se desenvolver e aprender com o que foi vivido (SERRÃO, 2018). Assim como, pode também ser associada a autocompaixão de forma negativa, com um baixo nível, em que, como citado pela autora, os idosos podem fugir ou se afastar dos sentimentos ruins como forma de escape, fazendo com que essas emoções não sejam vistas e nem trabalhadas pela pessoa ao longo da sua vida.

Por outro lado, a idade quando relacionada com a satisfação de vida do participante não possui relação, pois a mudança de idade vem acompanhada de inúmeras alterações na vida do indivíduo, seja de comportamento, de autoconceito, ou de novos papéis que requerem adaptações (RESENDE et al. 2006). Logo, essas mudanças podem ou não gerar satisfação no indivíduo, fazendo com que esse fator (idade) não seja determinante quando se trata de satisfação da vida, além disso, por haver pouca discussão sobre o tema da satisfação da vida relacionado com a idade das pessoas, cria-se a hipótese de que essa correlação não seja tão forte pela questão de que a satisfação da vida não depende apenas da idade do indivíduo, mas sim da maneira como a vida foi vivida e aproveitada. Percebe-se também que este tema pode ser relevante para o estudo da satisfação da vida, e por isso mais estudos futuros poderiam investigar o tema.

- Correlação entre Autocompaixão/Satisfação da vida e local de residência do Participante:

Quadro 4: Correlação entre autocompaixão/satisfação da vida e local de residência do participante

\begin{tabular}{|c|c|c|c|}
\hline & & $\begin{array}{l}\text { Nível de Satisfação da } \\
\text { vida do participante }\end{array}$ & $\begin{array}{c}\text { Nível de } \\
\text { Autocompaixão do } \\
\text { participante }\end{array}$ \\
\hline & Correlação de Pearson & $-0,111$ & $-0,154$ \\
\hline Onde o participante reside & Significância & 0,596 & 0,463 \\
\hline
\end{tabular}

Fonte: Própria (2019). 
Como resultado da correlação entre autocompaixão e local onde o participante reside, foi encontrado um coeficiente de -0,154 (Quadro 4), o que demonstra que a correlação é negativa (inversa), porém insignificante. Além disso, a correlação entre a satisfação de vida e o local de residência do participante apresentou um coeficiente de -0,111 (Quadro 4) também demonstrando ter uma correlação negativa/inversa insignificante. Uma correlação negativa (inversa) significa que as variáveis são opostas, e dessa forma, elas se desenvolvem proporcionalmente inversas, sendo assim, enquanto a autocompaixão e a satisfação da vida se desenvolvem, o local de moradia não necessariamente interfere nesse desenvolvimento, tornando então indiferente a mudança do local de residência ou não.

Dentre os locais de residência analisados, estavam lares/residenciais para idosos, casas de familiares, ou residir sozinho. Com o resultado obtido do coeficiente de Pearson, pode-se perceber que o local onde esses indivíduos se encontram não interfere na autocompaixão ou na satisfação de vida que possuem. Essa falta de correlação pode gerar como hipótese o fato de que a satisfação da vida e a autocompaixão independem do local aonde o idoso reside, pois o que influencia é a rede de apoio/rede familiar na qual está inserido. Logo, o espaço físico não se torna relevante para a forma como o indivíduo irá avaliar a sua vida e avaliar a si mesmo.

Muitos idosos, com a chegada da velhice, passam a viver em lares de longa permanência ou instituições de apoio. Essa mudança de um lar familiar para uma instituição pode ser um grande desafio para o idoso por gerar alterações no estilo de vida, por ser visto como perda de liberdade, abandono por parte dos filhos, pela ansiedade gerada tanto pelo tratamento como pela mudança ou mesmo pela ideia da proximidade da morte e o medo por ela gerada (JUNIOR e TAVARES, 2004). Entretanto, para outros indivíduos, essa instituição pode cumprir o papel de "lar", tornando-se assim um ponto de referência para um envelhecimento seguro e apropriado (JUNIOR e TAVARES, 2004).

Entretanto, essa mudança não está associada à autocompaixão que eles têm por si ou com a satisfação da vida. Além disso, os laços sociais podem dar suporte emocional e ajudar a minimizar o estresse, dessa forma, indivíduos que mantêm contato com os outros possuem hábitos mais saudáveis, assim como, possuem mais controle pessoal (RESENDE et al., 2006). Além disso, o fato de possuir uma rede de contato social ajuda a reduzir o isolamento social, podendo então ajudar com a satisfação da vida. Entretanto, essas relações sociais não são específicas do local aonde residem, ou seja, mesmo morando em casas com seus familiares, ou em instituições de repouso, o indivíduo pode manter e criar novos laços e redes sociais, fazendo com que a autocompaixão e a satisfação da vida não estejam vinculadas à um local específico. 
Com a pequena quantidade de estudos sobre a correlação entre essas variantes, percebese que este tema poderia ser discutido e pesquisado futuramente, visando entender melhor como se dá a relação do local de residência e a autocompaixão dos seres humanos.

\section{- Correlação entre Autocompaixão/Satisfação da vida e percepção sobre a saúde do participante:}

Quadro 5: Correlação entre autocompaixão/satisfação de vida e a saúde do participante

\begin{tabular}{|l|r|r|}
\hline & $\begin{array}{c}\text { Nível de Satisfação da } \\
\text { vida do participante }\end{array}$ & $\begin{array}{c}\text { Nível de } \\
\text { Autocompaixão do } \\
\text { participante }\end{array}$ \\
\hline \multicolumn{1}{|c|}{ Correlação de Pearson } & $0,701^{*}$ & 0,035 \\
$\begin{array}{l}\text { Como o participante considera } \\
\text { a sua saúde }\end{array}$ & 0,000 \\
*Correlação é significante até o nível $0,05$. & 0,868 \\
Fonte: Própria (2019).
\end{tabular}

Em relação à correlação da autocompaixão com a forma como o participante percebe a sua saúde, o coeficiente de Pearson obteve uma correlação de 0,035 (Quadro 5), o que demonstra ser uma correlação insignificante. Quando comparada a satisfação de vida com a percepção de saúde, o coeficiente foi de 0,701 (Quadro 5), mostrando assim uma correlação muito forte entre as a percepção da saúde e a satisfação da vida do participante.

A autocompaixão em idosos pode estar associada de forma positiva com a saúde (mental e física) e com o bem-estar, assim como com a satisfação de vida. Enquanto que de forma negativa, pode aparecer associada com a dor, problemas emocionais e sintomas depressivos. (ALLEN et al. 2012 apud PARENTE, 2016). Além disso, idosos com maiores níveis de autocompaixão podem apresentar melhores estratégias de enfrentamento, e sendo assim, podem se sentir menos constrangidos com suas dificuldades no geral, sendo elas físicas ou de memórias e outras (ALLEN et al. 2012 apud PARENTE, 2016).

Com a aplicação da escala e do questionário sociodemográfico, pôde-se perceber que a autocompaixão não teve um valor expressivo quando comparada com a percepção que cada indivíduo possui da sua saúde, o que pode significar que o nível de autocriticismo em relação à saúde dos participantes esteja mais forte, pois de forma geral, os indivíduos costumam ser mais duros e críticos consigo mesmos quando relacionado à sua saúde, e acabam sendo mais bondosos com os outros, fazendo com que a compaixão pelo próximo seja alto, porém a 
compaixão consigo mesmo (autocompaixão) seja baixa.

Entretanto, a satisfação de vida teve uma maior correlação com a saúde, apresentando uma forte relação entre as duas variáveis, dessa forma, de acordo com Allen et al., 2012; Clegg et al., 2013; Phillips e Ferguson, 2013 (apud PARENTE et al. 2018, p.22):

\begin{abstract}
A apreciação que os idosos fazem das suas vidas, que reflete o quão distantes se encontram das suas expectativas e desejos, poderá influenciar a percepção que têm da sua saúde física. Também a idade pode influenciar esta componente da saúde de forma negativa, ou seja, à medida que se vai envelhecendo, a probabilidade de surgirem problemas de saúde aumenta
\end{abstract}

Logo, a satisfação de vida do idoso está diretamente ligada à forma como ele percebe a sua saúde, pois quanto mais próxima ela se encontra do seu "ideal de saúde" melhor será a satisfação com a vida. Pessoas idosas costumam perceber a saúde como um forte elemento quando relacionado à qualidade de vida, fazendo com que a falta de saúde seja vista como um motivo gerador de infelicidade (RYFF 1989 apud JOIA et al. 2006).

\title{
- Correlação entre Autocompaixão/Satisfação da vida e situação financeira do participante:
}

Quadro 6: Correlação entre autocompaixão/satisfação da vida e situação financeira do participante

\begin{tabular}{|l|r|r|}
\hline & $\begin{array}{c}\text { Nível de Satisfação da } \\
\text { vida do participante }\end{array}$ & $\begin{array}{r}\text { Nível de Autocompaixão } \\
\text { do participante }\end{array}$ \\
\hline $\begin{array}{l}\text { Situação financeira do } \\
\text { participante }\end{array}$ & $\begin{array}{r}\text { Correlação de Pearson } \\
\text { Significância }\end{array}$ & $-0,226$ \\
\hline
\end{tabular}

Fonte: Própria (2019)

A correlação entre a autocompaixão e a situação financeira do participante de acordo com o coeficiente de Pearson, é de -0,048, (Quadro 6) demonstrando assim existir uma correlação negativamente inversa e insignificante entre às variáveis. Quanto à satisfação de vida, quando comparada ao estado financeiro do participante, o coeficiente foi de $-0,226$ (Quadro 6) demonstrando também ser uma correlação negativa (inversa) e sem significância entre as variáveis. Dessa forma, mesmo sendo proporcionalmente inverso, os resultados da correlação não são suficientemente fortes para terem influencia um sobre o outro.

A partir dos resultados da análise de correlação, dentre os 25 participantes, 19 deles consideram a sua situação financeira regular e 6 deles consideram boa. Surge então, como 
hipótese a questão de que a situação financeira do indivíduo, por ser uma percepção particular de cada um, e por ser algo que está no presente desses sujeitos, não afeta a forma como eles interpretaram as suas vidas até agora. Essa avaliação da situação financeira atual é algo subjetivo e por este motivo, cada indivíduo interpreta de forma pessoal, não tendo assim um marcador ou uma média do que a pessoa considere "bom, regular ou ruim" (CAMPARA, VIEIRA e POTRICH, 2017).

Além disso, a satisfação da vida é o reflexo de uma avaliação pessoal que o indivíduo faz sobre determinados pontos da vida, assim como, é um processo de juízo feito com base em algum critério próprio, variáveis como o estado financeiro podem não influenciar de forma eficaz nesse juízo realizado (RESENDE et al., 2006). Dessa forma, a satisfação da vida, "reflete o bem-estar individual, ou seja, o modo e os motivos que levam as pessoas a viverem suas experiências de vida de maneira positiva” (DIOGO, 2003 apud RESENDE et al., 2006 web). Logo, cada pessoa pode ver a sua vida como satisfatória ou não, dependendo de como interpreta a qualidade, o seu bem-estar e a forma como consegue enfrentar os desafios diários (RESENDE et al., 2006).

Dessa forma, pensar em como o indivíduo classifica a qualidade da sua vida, não necessariamente remete à condição financeira na qual se encontra nos dias atuais. Outra questão analisada é a de que a estabilidade financeira pode gerar uma ausência de preocupações ligadas ao dinheiro, como por exemplo contas, dívidas e etc. (CAMPARA, VIEIRA e POTRICH, 2017). Porém, a ausência de preocupações não se torna responsável por um maior nível de autocompaixão, já que a autocompaixão busca a não evitação de problemas ou de emoções, mas sim, formas de lidar com essas situações.

Logo, com a pouca quantidade de referencial teórico e de discussões realizadas sobre o tema do estado financeiro e da satisfação/autocompaixão dos indivíduos, percebe-se uma oportunidade para novas e futuras pesquisas que busquem relacionar essas variáveis.

\section{Considerações finais}

O presente estudo buscou, com a aplicação do questionário sociodemográfico e das escalas de autocompaixão/satisfação da vida, entender e avaliar o nível de autocompaixão e satisfação da vida em idosos. Dessa forma, com as categorias de análise de dados, pôde-se perceber que as hipóteses de que uma maior autocompaixão resultaria num maior autocuidado e de que idosos institucionalizados apresentam um maior grau de autocompaixão do que idosos 
que residem sozinhos não foram confirmadas. Entretanto, as hipóteses de que uma maior autocompaixão gera uma melhor qualidade de vida, e de que existe relação entre um alto nível de autocompaixão e uma maior satisfação da vida em idosos obtiveram respostas satisfatórias, confirmando as hipóteses propostas.

Desse modo, os resultados demonstram que, para os idosos participantes, o nível de autocompaixão e de satisfação se mostrou elevado, com mais de $70 \%$ deles com percentis altos e médios em ambos os constructos. O que demonstra que o grupo de idosos avaliado possui a capacidade de cuidar de si mesmo sem se autocriticar e punir em excesso, tornando assim o processo da velhice mais satisfatório e saudável.

Em relação à metodologia utilizada pelo presente estudo, acredita-se que a correlação do coeficiente de Pearson proporcionou uma visão mais ampla sobre o tema, possibilitando entender quais pontos são mais ou menos importantes para a autocompaixão e para a satisfação da vida.

Além disso, com base nas análises realizadas percebe-se que o tema da autocompaixão e da satisfação da vida em idosos deve ser estudado com maior profundidade em distintos aspectos da vida dos idosos de diferentes classes sociais e grupos culturais, assim como da população em geral, pois, com base nas limitações da pesquisa, por ter poucos estudos realizados e com a dificuldade de encontrar discussões sobre o tema, acredita-se ser de grande relevância, que sejam realizados futuros estudos que busquem discutir e analisar essa questão. Por fim, o estudo sobre a autocompaixão e a satisfação da vida se mostrou eficaz ao abarcar questões presentes na vida de todos os indivíduos avaliados, trazendo fatores como saúde, moradia e vivências no geral.

\section{Referências}

BICALHO, Maria A.C; CINTRA, Marco T.G. Modificações fisiológicas sistêmicas no envelhecimento. IN: MALLOY-DINIZ, Leandro F; FUENTES, Daniel. COSENZA, RAMON M. Neuropsicologia do envelhecimento: uma abordagem multidimensional. Sociedade brasileira de neuropsicologia, s.l. editora Artmed,. 2013. Cap.2, p.43-63

CARAMANO, Ana Amélia. Envelhecimento da população brasileira: uma contribuição demográfica. $2002 . \quad$ Disponível em: http://repositorio.ipea.gov.br/bitstream/11058/2091/1/TD_858.pdf. Acesso em: 01 de abr. 2019. 
CAMPARA, Jéssica Pulino; VIEIRA, Kelmara Mendes; POTRICH, Ani Caroline Grigion. Satisfação Global de Vida e Bem-estar Financeiro: desvendando a percepção de beneficiários do Programa Bolsa Família. Revista de Administração Pública, Rio de Janeiro, 2017. Disponível em: http://bibliotecadigital.fgv.br/ojs/index.php/rap/article/viewFile/65601/63375. Acesso em: 30 de set. 2019.

FREITAS, Eduarda R; BARBOSA, Altemir J. G; NEUFELD, Carmem B. Terapias cognitivocomportamentais com idosos. Novo Hamburgo, Editora sinopsys, $1^{\mathrm{a}}$ ed. 2015.

FONTINHA, Jorge M.G.M. "Faz a ti mesmo aquilo que farias ao próximo": Estilo de vinculação como determinante da compaixão e auto-compaixão. Universidade de Lisboa, Faculdade de psicologia e de ciências da educação, 2009.

GILBERT, Paul. As origens e a natureza da terapia focada na compaixão. British Journal of Clinical Psychology, p. 6-41, 2014.

Uma introdução à terapia focada na compaixão na terapia cognitivocomportamental. International Journal of Cognitive Therapy, p. 97-112, 2010

HUTZ, Claudio Simon. Avaliação em psicologia positiva. Porto Alegre, Editora Artmed $1^{\text {a }}$ ed. 2014.

Avaliação em psicologia positiva - Técnicas e medidas. $s . l$. Editora Hogrefe $1^{\mathrm{a}}$ ed. 2016.

JOIA, Luciane Cristina, et.al. Condições associadas ao grau de satisfação com a vida entre a população de idosos. São Paulo, UNESP, 2006. Disponível em: https://www.scielosp.org/scielo.php?pid=S003489102007000100018\&script=sci_arttext\&tlng $=$ en. Acesso em: 05 de abr. 2019.

JOIA, Luciane Cristina; RUIZ, Tânia. Satisfação com a Vida na Percepção dos Idosos. Revista Kairós Gerontologia,16(6), pp.79-102 São Paulo, 2013.

JUNIOR, R. C. F; TAVARES, M. F. L. A saúde sob o olhar do idoso institucionalizado: conhecendo e valorizando a sua opinião. Rio de Janeiro, 2004. Disponível em: https://www.scielosp.org/scielo.php?pid=S141432832005000100012\&script=sci_arttext\&tlng =en. Acesso em: 04 de abr. 2019.

MALOY-DINIZ, Leandro F; FUENTES, Daniel; CONSENZA, Ramon M. Neuropsicologia do envelhecimento: uma abordagem multidimensional. Editora Artmed. Porto Alegre, 2013. 
MOREIRA, virgínia; NOGUEIRA, Fernanda Nícia Nunes. Do indesejável ao inevitável: A experiência vivida do estigma de envelhecer na contemporaneidade. PSICOL.USP, São Paulo, Jan/mar 2008. Disponível: https://www.revistas.usp.br/psicousp/article/view/41952/45620. Acesso em: 01 de abr. 2019.

NERI, Anita Liberalesso. Conceitos e teorias sobre o envelhecimento. IN: MALLOY-DINIZ, Leandro F. FUENTES, Daniel. COSENZA, RAMON M. (Orgs.). Neuropsicologia do envelhecimento: uma abordagem multidimensional. Sociedade brasileira de neuropsicologia, editora Artmed, 2013. cap.1, p. 17-42.

OMS. Relatório mundial de envelhecimento e saúde. 2015. Disponível em: https://sbgg.org.br/wp-content/uploads/2015/10/OMS-ENVELHECIMENTO-2015-port.pdf. Acesso em: 25 de mar. 2019.

ONUBR. Saúde mental depende de bem-estar físico e social, diz OMS em dia mundial. 2016. Disponível em: nacoesunidas.org. Acesso em: 31 de out. 2019.

PAIVA, Ana Tarcia Guimarães et.al. Avaliação da funcionalidade de famílias com idosos. Cogitare enfermagem, vol16, nº Curitiba, 2011. Disponível em: https://www.redalyc.org/pdf/4836/483648966003.pdf. Acesso em: 29 de mar. 2019

PARENTE, Liliana Filipa Dias. Autocompaixão, bem-estar subjetivo e estado de saúde em idosos. 2016. Dissertação (Mestrado em psicologia clínica) - Instituto superior Miguel Torga, Coimbra.

PARENTE, Liliana Filipa Dias et.al. Autocompaixão, bem-estar subjetivo e estado de saúde na idade avançada. Revista Portuguesa de Investigação Comportamental e Social 2018, Vol. 4.

PEREIRA, Esmeralda Maria F.T. Vinculação, autocompaixão e resiliência em jovens adultos: relações com as competências sociais. Universidade Lusófona de Humanidades e Tecnologias. Escola de Psicologia e Ciências da Vida, Lisboa, 2016. Disponível em: http://recil.grupolusofona.pt/bitstream/handle/10437/7119/Tese\%20\%20Final\%20_\%20Esme ralda\%20P._enviada\%20a\%20\%209\%2001\%202015_\%20Lus\%c3\%b3fona\%20_\%20corrigi da\%20\%20depois $\% 20$ de $\% 20$ entregue $\% 20$ com $\% 20$ interpreta $\%$ c3\%a7\%c3\%a3o $\% 20$ de $\% 20 \%$ 20todos\%20 1.pdf?sequence=1. Acesso em: 29 de set. 2019.

SERRÃO, Carla. Mindfulness e Autocompaixão na idade avançada. Repositório Científico do Instituto Politécnico do Porto, 2018. Disponível em: 
https://recipp.ipp.pt/bitstream/10400.22/12108/1/Cap.\%20MAIA_Proj\%20Intergeracional_C S.pdf. Acesso em: 30 de set. 2019.

RESENDE, Marineia Crosara de. et al. Rede de relações sociais e satisfação com a vida de adultos e idosos. Centro Universitário do Triângulo, Uberlândia. Revista Psicol. Am. Lat. n.5 México fev. $2006 . \quad$ Disponível em: http://pepsic.bvsalud.org/scielo.php?script=sci_arttext\&pid=S1870-350X2006000100015. Acesso em: 29 de set. 2019.

VERAS, Renato. Envelhecimento populacional contemporâneo: demandas, desafios e inovações. Revista de Saúde Pública, Rio de Janeiro, 2009. Disponível em: https://www.scielosp.org/pdf/rsp/2009.v43n3/548-554/pt. Acesso em: 04 de abr. 2019.

VERAS, Renato et.al. Velhice numa perspectiva de futuro saudável. UNATI, Universidade aberta da terceira Idade, Rio de Janeiro, 2001. Disponível em: http://www.miniweb.com.br/cantinho/3_idade/artigos/PDF/unati2.pdf\#page=98. Acesso em: 17 de mar. 2019. 